\title{
An Overview on Atypical Pneumonia Clinical Features and Management Approach
}

\author{
Ehdaa Ali Al-Abbad', Yousef Ahmed I Albarrak ${ }^{2}$, Nawaf Ibrahim Al Shuqayfah ${ }^{3}$, Ali Adnan Nahhas ${ }^{4}$, Abdulrahman Fahad Alnemari, \\ Razan Khalid Alqurashi ${ }^{5}$, Safiah Hussain M Abu Thiyab ${ }^{6}$, Mona Khalid Alqubali ${ }^{7 *}$, Malak Atallah Alhawiti ${ }^{8}$, Sarah Mathkar Almutairi ${ }^{9}$, \\ Meshal Ali Murshed Alanazi ${ }^{10}$, Majed Mansour Nawar Aljuaid ${ }^{11}$ \\ ${ }^{1}$ Faculty of Medicine, King Faisal University, Al Ahsa, KSA. ${ }^{2}$ Faculty of Medicine, Imam Mohammed Bin Saud Islamic University, Riyadh, KSA \\ ${ }^{3}$ Faculty of Medicine, King Khalid University, Abha, KSA. ${ }^{4}$ Faculty of Medicine, King Abdulaziz University, Jeddah, KSA. ${ }^{5}$ Faculty of Medicine, \\ Ibn Sina National College of Medicine, Jeddah, KSA. ${ }^{6}$ Faculty of Medicine, Jazan University, Jazan, KSA. ${ }^{7}$ Faculty of Medicine, Tabuk \\ University, Tabuk, KSA. ${ }^{8}$ Faculty of Medicine, Tabuk University, Tabuk, KSA. ${ }^{9}$ Faculty of Pharmacy, Qassim University, Qassim, KSA. \\ ${ }^{10}$ Faculty of Medicine, Aljouf University, Aljouf, KSA. ${ }^{11}$ Emergency Department, King Abdul Aziz Specialist Hospital, Taif, KSA.
}

\section{Abstract}

Atypical pneumonia has evolved in recent decades to signify lower respiratory tract diseases caused by certain respiratory pathogens. These pathogens are distinguished clinically and radiologically from typical bacterial community-acquired pneumonia (CAP). The spectrum of such infections includes zoonotic and non-zoonotic transmissions, with the latter being more common. The tendency of extrapulmonary involvement, which is true for each kind of atypical CAP, distinguishes clinically from classical CAP. Therefore, clinical syndromic diagnosis is important for raising the index of suspicion and commencing appropriate empirical antibiotic therapy and prompting further diagnostic testing. We aimed to review the literature to enhance the understanding and awareness of atypical pneumonia. We reviewed the literature for atypical pneumonia; clinical manifestations, approach to diagnosis, and management. Articles were chosen from the PubMed database, and selected studies were subjected to a thorough review. Atypical organisms that cause pneumonia are more likely to cause systemic disorders with a wide range of extrapulmonary symptoms. On the other hand, some of them are difficult to culture and dangerous to isolate. As a result, clinical syndromic diagnosis is crucial for raising the index of suspicion, commencing appropriate empirical antibiotic therapy, and promoting specific diagnostic tests.

Keywords: Atypical pneumonia, Mycoplasma pneumoniae, Legionnaire's disease

\section{INTRODUCTION}

Previously, the term "atypical pneumonia" was applied for viral community-acquired pneumonia (CAP) that were distinguished both clinically and radiologically from bacterial CAPs. In recent decades, atypical pneumonia has emerged to indicate lower respiratory tract illnesses caused by particular respiratory pathogens. These include three zoonotic organisms: Chlamydia psittaci, Francisella tularensis, and Coxiella burnetiid. Moreover, there are three non-zoonotic organisms: Mycoplasma pneumoniae, Chlamydia pneumoniae, and Legionella [1-3]. Clinical differentiation from classical CAP is made by the tendency of extrapulmonary involvement that is true for each type of atypical CAPs $[1,2]$. In this review, we shed the light on the clinical features and management of atypical pneumonia.

\section{Materials and Methods}

We utilized the PubMed database for the selection process of relevant articles, and the following keys used in the mesh ((“Atypical Pneumonia"[Mesh]) AND ("Clinical Features"[Mesh] AND "Diagnosis"[Mesh] AND "Approach"[Mesh] AND ("Management"[Mesh])). For the inclusion criteria, the articles were selected based on including one of the following: atypical pneumonia's clinical presentation, diagnosis, and treatment. Exclusion criteria were all other articles that did not meet the criteria by not having any of the inclusion criteria results in their topic.

\section{Review}

Atypical CAPs account for around 15\% of all CAPs cases. Atypical pneumonia organism outbreaks do occur in the community, however; most cases of atypical CAP are sporadic. As community outbreaks, atypical pneumonia can cause outbreaks of nursing home-acquired pneumonia

Address for correspondence: Mona Khalid Alqubali, Faculty of Medicine, Tabuk University, Tabuk, KSA. mona.alqubali @gmail.com

This is an open-access article distributed under the terms of the Creative Commons Attribution-Non Commercial-Share Alike 3.0 License, which allows others to remix, tweak, and build upon the work non commercially, as long as the author is credited and the new creations are licensed under the identical terms.

How to cite this article: Al-Abbad E A, Albarrak Y A I, Al Shuqayfah N I, Nahhas A A, Alnemari A F, Alqurashi R K, et al. An Overview on Atypical Pneumonia Clinical Features and Management Approach. Arch. Pharm. Pract. 2022;13(1):2430. https://doi.org/10.51847/CHgE98elpC 
(NHAP) or nosocomial pneumonia (NP) but they are usually rare. In individuals with mild or walking CAP, atypical pathogens are more common than typical bacterial pathogens. In hospitalized patients, Legionella is a common cause of severe CAP [2-4].

\section{Etiology}

Clinically, atypical pneumonia can be divided into two groups: those that are transmitted zoonotically and those that are not. The zoonotic transmission includes psittacosis, Q fever, and tularaemia which are caused by Chlamydia psittaci, Francisella tularensis, Coxiella burnetiid, respectively. On the other hand, non-zoonotic transmission comprises Mycoplasma, Chlamydia pneumoniae, and Legionella. Both types of transmission that manifest as atypical pneumonia differ essentially from bacterial CAPs [13]. In fact, the hallmark of difference is the existence or nonexistence of extrapulmonary organ implications. Atypical pneumonia manifests mainly as a systemic infectious disease with a pulmonary element, i.e., pneumonia. On the contrary, typical CAPs such as that caused by Streptococcus pneumoniae, present with both clinical and laboratory findings relatively restricted to the lungs. Once this distinction is established between typical and atypical CAPs, the physician can assess the typical pattern of organ involvement and cut down the diagnostic alternatives $[1-3,5]$.

\section{Pathogenesis \& Clinical Presentation Mycoplasma Pneumoniae}

Mycoplasmas are classified as bacteria and are interestingly the smallest free-living organisms [6]. There are two main subtypes of this bacteria, type 1 and type 2. Communityacquired respiratory distress syndrome (CARDS) toxin, which has been demonstrated to be a virulence factor triggering vacuolization and may play a role in respiratory epithelium degradation, is expressed more frequently in type 2 strains [2, 7, 8]. Moreover, type 2 also produces a very durable biofilm, which may protect the organism from antibiotic penetration and the immunological response of the host [8].

M. pneumoniae is one of the most frequent bacteria that inflicts upper respiratory tract infection (URI), acute bronchitis, and CAP. According to serologic surveys, roughly $1 \%$ of the US population is infected with M. pneumoniae each year [9]. Furthermore, young children are more likely than adolescents and adults to get CAP caused by M. pneumoniae. It is spread mostly by respiratory droplets from one person to another [10]. After exposure, the incubation period usually lasts two to three weeks. Moreover, during non-epidemic periods, infection rates tend to surge in the summer and peak in the late fall or winter [10-12].

Clinical manifestations range from the asymptomatic carriage and upper respiratory tract infections; such as acute bronchitis and pneumonia, to extrapulmonary manifestations that are considered fairly rare [13]. Asymptomatic infections appear to be widespread, and symptomatic illness can lead to a protracted carriage. The asymptomatic carriage can last for weeks to months after an acute state, with a median of approximately seven weeks [14].

The most common features of M. pneumoniae infection are upper respiratory tract infection (URI) and acute bronchitis. The clinical signs and symptoms of M. pneumoniae-caused URI and acute bronchitis are similar to those of other causatives. These comprise cough, sore throat, rhinorrhea, coryza, and otalgia. Cough is a common symptom that can be productive or nonproductive and may be accompanied by wheezing $[15,16]$. Coughing that is persistent or protracted is the main symptom of acute bronchitis. URIs and acute bronchitis produced by M. pneumoniae are frequently selflimited, similar to URIs and acute bronchitis inflicted by other causatives such as viruses [17].

For pneumonia, it is usually community-acquired and presentation differs with the stage of the disease [16]. The onset of illness is gradual, and symptoms such as headache, malaise, low-grade fever, and sore throat may be present. Cough (either wet or dry) is common, and pleuritic chest pain or shortness of breath may accompany it. Coughing may cause chest pain, which is a common ailment. Other URI features, such as rhinorrhea, sinusitis, otitis media, and cervical adenopathy, can occur alongside pneumonia. Moreover, Dyspnea, hypoxemia, hypotension, and altered mental status may manifest, but they are less frequent in comparison to CAP caused by other causatives $[18,19]$.

Extrapulmonary manifestations can occur concurrently with or separately of respiratory-tract disease. While $\mathbf{M}$. pneumoniae infection has been linked to a variety of illnesses, only a handful have been proven to be causal. Hemolysis, CNS disease, dermatitis, carditis, joint disease, and gastrointestinal disease are only a few of them [18]. In roughly $60 \%$ of instances, $M$. pneumoniae infection is accompanied by hemolysis, which is usually mild. Mycoplasma causes a change in the I antigen on the erythrocytes' membrane during infection. As a result, IgM autoantibodies are generated and target this antigen, resulting in immune-mediated hemolysis (also called cold agglutinin disease) [20]. Hemolysis is self-limiting in most patients, and no transfusion or immunosuppressive medication is required. Hemolysis can be severe and life-threatening in some patients, especially those with comorbid hematologic abnormalities such as sickle cell disease [21, 22].

CNS symptoms occur in about $0.1 \%$ of all patients with $\mathrm{M}$. pneumoniae infections, and up to $7 \%$ of those who require admission. CNS involvement is more common in youngsters than it is in adults. A history of an antecedent respiratory infection is generally, but not always, observed in cases of CNS manifestations caused by $\mathrm{M}$. pneumoniae. The most prevalent CNS feature is encephalitis. Meningitis, peripheral neuropathy, Guillain-Barré syndrome (GBS), transverse myelitis, acute disseminated encephalomyelitis (ADEM), 
cranial nerve palsies, and cerebellar ataxia are some of the other features of CNS involvement [23, 24].

Cutaneous and mucocutaneous symptoms are rather more frequent extrapulmonary presentations of $\mathrm{M}$. pneumoniae infection. These comprise maculopapular or vesicular rashes, urticaria, erythema multiforme, Stevens-Johnson syndrome, and M. pneumoniae-induced rash and mucositis (MIRM). The presence of concurrent or prior respiratory symptoms is common, but not necessarily significant. Notably, some of the cutaneous symptoms are caused by bacterial infection, whereas others are caused by immunological responses $[25$, 26].

\section{Chlamydia Pneumoniae}

The pathogenesis of C. pneumoniae is influenced by its biphasic life cycle. The organism exists as a small, dense elementary body outside of the host. This elementary body has a rigid wall that gives the organism the ability to survive outside the host for a short period. Once it infects the host, this elementary body adheres to respiratory mucosal epithelial cells and gets inside the cell via receptor-mediated endocytosis. Inside the cell, the organism persists and replicates within the phagosome for the next 36 to 72 hours, generating hundreds of copies that are subsequently released outside the cell. Interestingly, Chlamydial antigens are released onto the host cell surface during replication, triggering an immunological response. Therefore, one of the most important characteristics of Chlamydia organisms is that the immunity to infection is short-lived. As a result, it's possible to get infected again [27].

In terms of clinical symptoms, M. pneumoniae and C. pneumoniae CAP are very similar, although there are a few key differences. To begin with, M. pneumoniae is an acute infectious disease, whereas C. pneumoniae might be acute but is usually a chronic infection $[1,3]$. Secondly, Otitis, bullous myringitis, and moderate non-exudative pharyngitis are common upper respiratory tract symptoms of $\mathrm{M}$. pneumoniae in CAP patients, while in C. pneumoniae CAP these findings are less common $[28,29]$. Thirdly, the presence or absence of laryngitis is one of the most essential clinical findings for distinguishing Mycoplasma from C. pneumoniae. Although not all C. pneumoniae CAP patients get laryngitis, the majority do. Hence, individuals who appear with a 'mycoplasma-like illness' and hoarseness due to pneumonia should be assumed to have C. pneumoniae until the contrary is demonstrated. On the other hand, until proven otherwise, patients with CAP, upper respiratory tract involvement, and highly raised cold agglutinin titers should be deemed to have M. pneumoniae CAP. Moreover, cardiac or pulmonary involvement is not characteristic of $\mathrm{M}$. pneumoniae or $\mathrm{C}$. pneumoniae infections. Gastrointestinal involvement is frequent in Mycoplasma pneumonia, but not so much in C. pneumoniae pneumonia [29-32].

\section{Legionella}

Legionella is a part of a clinical syndrome called legionellosis that comprises two associated infections, Legionnaires' disease (i.e., pneumonia) and Pontiac fever [33]. Pathogenesis of legionnaire's disease is highlighted by Legionella's invasion of alveolar macrophages and intracellular proliferation after being delivered by aerosol inhalation $[34,35]$.

Even though no clinical symptoms reliably identify Legionnaires' disease from other types of pneumonia, several characteristics may raise the suspicion level. These comprise Gastrointestinal manifestations such as nausea, vomiting, and diarrhea; hyponatremia; high liver enzymes levels; C-reactive protein levels $>100 \mathrm{mg} / \mathrm{L}$; and failure to respond to conventional treatment of pneumonia. Although scoring systems that combine these clinical and laboratory characteristics have been devised, none have been validated or demonstrated to have adequate diagnostic predictive value [36-39].

Fever, cough, and shortness of breath are the most common symptoms. Symptoms usually appear within 10 days following contact with polluted water or soil. Cough is frequently preceded by fever and fatigue [36, 37]. Extrapulmonary Legionella illness is a rare consequence of Legionella pneumonia, but it can also occur on its own. The majority of instances have been documented in patients who are immunocompromised [40]. The extrapulmonary manifestations that have been reported comprise meningitis, brain abscesses, surgical site infections, prosthetic joint infection, osteomyelitis, cellulitis, cutaneous and soft tissue abscesses, myocarditis, pericarditis, native valve and prosthetic valve endocarditis, peritonitis, and pyelonephritis [41-54]. Extrapulmonary illness is diagnosed by detecting Legionella at the afflicted site, which is commonly done with a culture or a polymerase chain reaction [39].

\section{Zoonotic Infections}

Psittacosis (caused by $C$. psittaci) usually manifests itself in young or middle-aged individuals as a sudden onset fever, a severe headache, and a dry cough, although asymptomatic infection is possible. The majority of patients have recent exposure to birds. Incubation lasts between 5 and 14 days on average but can last up to 39 days. Photophobia is often associated with headache, which is frequently severe. Pharyngitis, diarrhea, and impaired mental status are some of the less common but significant symptoms. Diarrhea affects up to a quarter of patients and is usually moderate. It can, however, be fairly severe, and in some cases, it may even be the most apparent symptom $[55,56]$.

Patients with psittacosis may have complications in a variety of organ systems. These are uncommon symptoms of the condition, but some of them can be serious. These include pulmonary disease (e.g., respiratory failure), renal disease (e.g., acute tubular necrosis, acute tubulointerstitial nephritis, acute proliferative glomerulonephritis), liver disease (e.g., Icteric hepatitis, nodules, granulomas), hematologic 
Al-Abbad et al.: An Overview on Atypical Pneumonia Clinical Features and Management Approach, Review Article

complications (e.g., hemolytic anemia, acute thrombocytopenic purpura, pancytopenia, thrombotic thrombocytopenic purpura), neurologic disease (e.g., encephalitis, meningitis, intracranial hypertension) and cutaneous disease (e.g., erythema nodosum, erythema multiforme, erythema marginatum, panniculitis) [57-61].

Tularemia infection (caused by Francisella tularensis) occurs after contact with infected animals or invertebrate vectors. It can cause anything from asymptomatic sickness to septic shock and death, depending largely on the virulence of the strain, portal of acquisition, and immunological status of the host [62]. Nonspecific systemic symptoms, such as fever, chills, anorexia, and malaise, commonly appear three to five days after exposure to tularemia. The fever may go away for a few days but returns fast. Headache, malaise, tightness in the chest, muscle pain, abdominal pain, vomiting, or diarrhea are some of the other nonspecific complaints. These symptoms may have subsided by the time of examination in some patients [63]. Depending on the portal of entry, patients usually have particular clinical symptoms associated with one of the six primary clinical types of tularemia when they seek medical help. These comprise ulceroglandular tularemia, glandular tularemia, oculoglandular tularemia, pneumonic tularemia, pharyngeal (oropharyngeal) tularemia, and typhoidal tularemia [62-65].

Q fever (caused by Coxiella burnetiid) is another zoonotic infection that causes atypical pneumonia. The pathogenesis of this organism is highlighted in the sense that macrophage is C. burnetii's most common host cell, however, it is unable to kill the bacteria. The fusion of cell lysosomes allows $\mathrm{C}$. burnetii to exist and replicate in a single, big, acidic vacuole. Furthermore, a sporulation-like process shields the pathogen from the outside environment, allowing it to persist for long durations of time [66]. Individuals become sick by inhaling dust contaminated with $\mathrm{C}$. burnetii via infected animal feces, urine, milk, or birth products. It is not necessary to have direct contact with an animal to become ill with $Q$ fever [67]. Individuals with $\mathrm{Q}$ fever have a wide range of symptoms. Whereas the clinical features of acute or chronic infection are substantial in certain persons, Q fever clinical manifestations are minimal or nonexistent in others. The majority of cases of $\mathrm{Q}$ fever pneumonia are mild, with individuals complaining of a dry cough and a high fever. On examination, such people show very minor auscultatory irregularities. Some patients, however, may have acute respiratory distress. The chest imaging findings are inconclusive and mimic viral pneumonia. Pleural effusion can also happen, but it is rare. Extrapulmonary manifestations, such as severe headaches, myalgias, and arthralgias, are common in addition to respiratory symptoms. Symptoms can persist from around one week to three weeks [67-69].

\section{Diagnostic Approach}

Atypical organisms are challenging to culture and isolate, and they can be hazardous. As a result, clinical syndromic diagnosis is critical for increasing diagnostic presumption, initiating proper empirical antibiotic medication, and triggering precise diagnostic testing. For the atypical organisms causing CAP, certain diagnostic testing is available [2, 5]. Direct fluorescent antibody (DFA) staining of sputum or respiratory secretions, pleural fluid, or lung tissues can quickly identify Legionella. After starting antiLegionella medication, DFA positivity in sputum drops significantly. The presence of a single titer of 1:512 on indirect fluorescent antibody testing (IFA) is also diagnostic. The Legionella antigen test has been beneficial in raising Legionella awareness and giving another L. pneumophila diagnostic test. Although a positive Legionella antigen assay is indicative of Legionella pneumophila, a negative result does not at all exclude out legionnaire's disease [38]. The Legionella antigen test has the benefit of remaining positive for several weeks after the onset of excretion of antigens in the urine (i.e., antigenuria) and long after the infection has been clinically resolved. Although Legionella pneumophila is the most prevalent Legionella species seen, the Legionella antigen test is confined to only these species. Antigenuria develops over several days in the course of legionnaire's disease. As with early serological testing, if the test is undertaken too soon, it may be falsely negative [33, 38, 49, $70]$.

In a specific viral medium, $\mathrm{M}$. pneumoniae and $\mathrm{C}$. pneumoniae can be cultured from respiratory secretions. $\mathrm{M}$. pneumoniae and $\mathrm{C}$. pneumoniae are most usually diagnosed by serology [71]. In a patient with CAP, an acutely increased M. pneumoniae or C. pneumoniae IgM titer is confirmatory. A four-fold elevation in $\operatorname{IgG} \mathrm{M}$. pneumoniae or $\mathrm{C}$. pneumoniae titers indicates previous exposure or infection but does not rule out acute or concomitant infection [72]. Due to the difficulty of isolating C. psittaci, diagnosis solely relies on serological tests. In nonimmune or formerly unexposed patients, elevated tube agglutination (TA) tests for C. psittaci are confirmatory [73]. Tularemia and $\mathrm{Q}$ fever are also diagnosed using serology, as these organisms are highly contagious, hazardous, and difficult to isolate $[62,68]$. Moreover, rapid increases of $\mathrm{F}$. tularensis $\mathrm{IgM} / \mathrm{IgG}$ titers in nonimmune, nonexposed people are conclusive [62]. The diagnosis of the zoonotic CAPs is established on a four-fold increase in titers across 4-8 weeks intervals of acute and convalescent specimens, excluding high initial acute titers for $\mathrm{Q}$ fever or tularemia $[2,72]$. Chronic $\mathrm{Q}$ fever infection, rather than acute infection, is indicated by persistently high $\mathrm{C}$. burnetii IgG levels [68].

Atypical pneumonia does not have a recognizable X-ray pattern in the chest. Tularemia and Legionella can cause pleural effusions, and M. pneumoniae can cause minor effusions. Legionella does not have a distinctive chest X-ray pattern, however quickly progressing asymmetrical infiltrates are common [74].

\section{Management}

Due to the unresponsiveness of 'atypical' bacteria to -lactam antibiotics, and the inability to perform standard sensitivity 
testing, empirical therapy with macrolides or novel fluoroquinolones is the mainstay of therapy. All present guidelines are based on in vitro testing, observational studies, and expert consensus in the face of limited clinical studies. Anti-atypical medications, primarily a combination of a respiratory fluoroquinolone and a macrolide plus $\beta$-lactam, are included in every community-acquired pneumonia guideline as a first-line treatment [75]. Combination therapy, which includes adding rifampicin to the fluorquinolone, has been tried across many serious and refractory cases identified as legionellosis, although its efficacy is still debatable. Treatment for 2 to 3 weeks is commonly deemed enough, however, this information is also not supported by substantial evidence [76, 77].

Once the microbiological diagnosis becomes available, the treatment of atypical pneumonia may also be targeted according to the pathogen. Atypical pneumonia therapy can also be tailored based on the organism once the microbiological confirmation is established. For Mycoplasma pneumoniae, doxycycline, macrolide, and novel fluoroquinolones (e.g., levofloxacin) are recommended. The same regimen is also recommended for Chlamydophila pneumoniae. For legionella, the recommended regimen is levofloxacin, a macrolide (preferably azithromycin) with or without rifampicin [78].

For zoonotic organisms, tetracyclines are usually the cornerstone treatment. This is true for pneumonia caused by C. psittaci. The preferred option of tetracyclines is doxycycline, owing to its superior pharmacokinetic qualities and lower frequency of gastrointestinal intolerance. Other options recommended for psittacosis comprises macrolides such as erythromycin or azithromycin, chloramphenicol, rifampin, and fluoroquinolones [78, 79]. The suggested treatment for $\mathrm{Q}$ fever is also doxycycline. Other alternatives for those intolerants to doxycycline include macrolides, trimethoprim-sulfamethoxazole, fluoroquinolones [78, 80]. For tularemia, drugs that have proven clinical efficacy comprise streptomycin and gentamicin (in particular), tetracyclines, fluoroquinolones, and chloramphenicol [62, 78].

\section{Conclusion}

Atypical organisms causing pneumonia tend to induce systemic diseases with a spectrum of extrapulmonary manifestations. Some of them, on the other hand, are difficult to culture and hazardous to isolate. As a result, clinical syndromic diagnosis is critical for increasing the index of suspicion, initiating adequate empirical antibiotic therapy, and encouraging specific diagnostic testing.

\section{ACKNOWLEDGMENTS: None CONFLICT OF INTEREST: None FINANCIAL SUPPORT: None ETHICS STATEMENT: None}

\section{REFERENCES}

1. Murray HW, Tuazon C. Atypical pneumonias. Med Clin North Am. 1980;64(3):507-27. doi:10.1016/S0025-7125(16)31607-8

2. Blasi F. Atypical pathogens and respiratory tract infections. Eur Respir J. 2004;24(1):171-82. doi:10.1183/09031936.04.00135703

3. Bartlett JG, Mundy LM. Community-acquired pneumonia. N Engl J Med. 1995;333(24):1618-24. doi:10.1056/NEJM199512143332408

4. Zumla A. Mandell, Douglas, and Bennett's principles and practice of infectious diseases. Lancet Infect Dis. 2010;10(5):303. doi:10.1016/S1473-3099(10)70089-X

5. Gupta SK, Sarosi GA. The role of atypical pathogens in communityacquired pneumonia. Med Clin. 2001;85(6):1349-65. doi:10.1016/S0025-7125(05)70384-9

6. Taylor-Robinson D. Infections due to species of Mycoplasma and Ureaplasma: an update. Clin Infect Dis. 1996;671-82. doi:10.1093/CLINIDS/23.4.671

7. Kannan TR, Baseman JB. ADP-ribosylating and vacuolating cytotoxin of Mycoplasma pneumoniae represents unique virulence determinant among bacterial pathogens. Proc Natl Acad Sci. 2006;103(17):6724-9. doi:10.1073/PNAS.0510644103

8. Simmons WL, Daubenspeck JM, Osborne JD, Balish MF, Waites KB, Dybvig, K. Type 1 and type 2 strains of Mycoplasma pneumoniae form $\begin{array}{lll}\text { different } & \text { biofilms. Microbiology. 2013;159(Pt } & 4): 737 .\end{array}$ doi:10.1099/MIC.0.064782-0

9. Foy HM, Kenny GE, Cooney MK, Allan ID. Long-term epidemiology of infections with Mycoplasma pneumoniae. J Infect Dis. 1979;139(6):681-7. doi:10.1093/INFDIS/139.6.681

10. Jain S, Self WH, Wunderink RG, Fakhran S, Balk R, Bramley AM, et al. Community-Acquired Pneumonia Requiring Hospitalization among U.S. Adults. N Engl J Med. 2015;373(5):415-27. doi:10.1056/NEJMOA1500245

11. Qu J, Yang C, Bao F, Chen S, Gu L, Cao B. Epidemiological characterization of respiratory tract infections caused by Mycoplasma pneumoniae during epidemic and post-epidemic periods in North China, from 2011 to 2016. BMC Infect Dis. 2018;18(1):1-8. doi: $10.1186 / \mathrm{S} 12879-018-3250-2$

12. Brown RJ, Nguipdop-Djomo P, Zhao H, Stanford E, Spiller OB, Chalker VJ. Mycoplasma pneumoniae Epidemiology in England and Wales: A National Perspective. Front Microbiol. 2016;7(FEB):157. doi:10.3389/FMICB.2016.00157

13. Spuesens EB, Fraaij PL, Visser EG, Hoogenboezem T, Hop WC, van Adrichem LN, et al. Carriage of Mycoplasma pneumoniae in the upper respiratory tract of symptomatic and asymptomatic children: an observational study. PLoS Med. 2013;10(5):e1001444. doi:10.1371/JOURNAL.PMED.1001444

14. Klement E, Talkington DF, Wasserzug O, Kayouf R, Davidovitch N, Dumke R, et al. Identification of risk factors for infection in an outbreak of Mycoplasma pneumoniae respiratory tract disease. Clin Infect Dis. 2006;43(10):1239-45. doi:10.1086/508458

15. Mansel JK, Rosenow EC, Smith TF, Martin JW. Mycoplasma pneumoniae pneumonia. Chest. 1989;95(3):639-46. doi:10.1378/CHEST.95.3.639

16. Waites KB, Xiao L, Liu Y, Balish MF, Atkinson TP. Mycoplasma pneumoniae from the Respiratory Tract and Beyond. Clin Microbiol Rev. 2017;30(3):747-809. doi:10.1128/CMR.00114-16

17. Wadowsky RM, Castilla EA, Laus S, Kozy A, Atchison RW, Kingsley LA, et al. Evaluation of Chlamydia pneumoniae and Mycoplasma pneumoniae as etiologic agents of persistent cough in adolescents and adults. J Clin Microbiol. 2002;40(2):637-40. doi:10.1128/JCM.40.2.637-640.2002

18. Lieberman D, Schlaeffer F, Lieberman D, Horowitz S, Horovitz O, Porath A. Mycoplasma pneumoniae community-acquired pneumonia: a review of 101 hospitalized adult patients. Respiration. 1996;63(5):261-6. doi:10.1159/000196557

19. Cunha CB. The First Atypical Pneumonia: The History of the Discovery of Mycoplasma pneumoniae. Infect Dis Clin North Am. 2010;24(1):1-5. doi:10.1016/J.IDC.2009.10.007

20. Loomes LM, Uemura KI, Childs RA, Paulson JC, Rogers GN, Scudder $\mathrm{PR}$, et al. Erythrocyte receptors for Mycoplasma pneumoniae are sialylated oligosaccharides of Ii antigen type. Nature. 1984;307(5951):560-3. doi:10.1038/307560A0 
Al-Abbad et al.: An Overview on Atypical Pneumonia Clinical Features and Management Approach, Review Article

21. Daxböck F, Zedtwitz-Liebenstein K, Burgmann H, Graninger W. Severe hemolytic anemia and excessive leukocytosis masking mycoplasma pneumonia. Ann Hematol. 2001;80(3):180-2. doi:10.1007/S002770000250

22. Al-Mendalawi MD. Anemic crisis due to Mycoplasma pneumoniae complication in sickle cell patients. Saudi Med J. 2009;30(8):1105-6.

23. Tsiodras S, Kelesidis I, Kelesidis T, Stamboulis E, Giamarellou H. Central nervous system manifestations of Mycoplasma pneumoniae infections. J Infect. 2005;51(5):343-54. doi:10.1016/J.JINF.2005.07.005

24. Koskiniemi M. CNS manifestations associated with Mycoplasma pneumoniae infections: summary of cases at the University of Helsinki and review. Clin Infect Dis. 1993;17 Suppl 1(Suppl 1):S52-S7. doi:10.1093/CLINIDS/17.SUPPLEMENT_1.S52

25. Tay YK, Huff JC, Weston WL. Mycoplasma pneumoniae infection is associated with Stevens-Johnson syndrome, not erythema multiforme (von Hebra). J Am Acad Dermatol. 1996;35(5 Pt 1):757-60. doi:10.1016/S0190-9622(96)90732-X

26. Canavan TN, Mathes EF, Frieden I, Shinkai K. Mycoplasma pneumoniae-induced rash and mucositis as a syndrome distinct from Stevens-Johnson syndrome and erythema multiforme: A systematic review. J Am Acad Dermatol. 2015;72(2):239-45. doi:10.1016/J.JAAD.2014.06.026

27. Burillo A, Bouza E. Chlamydophila pneumoniae. Infect Dis Clin North Am. 2010;24(1):61-71. doi:10.1016/J.IDC.2009.10.002

28. Grayston JT, Aldous MB, Easton A, Wang SP, Kuo CC, Campbell LA, et al. Evidence that Chlamydia pneumoniae causes pneumonia and bronchitis. J Infect Dis. 1993;168(5):1231-5. doi:10.1093/INFDIS/168.5.1231

29. Kauppinen MT, Saikku P, Kujala P, Herva E, Syrjälä H. Clinical picture of community-acquired Chlamydia pneumoniae pneumonia requiring hospital treatment: a comparison between chlamydial and pneumococcal pneumonia. Thorax. 1996;51(2):185-9. doi:10.1136/THX.51.2.185

30. Bochud PY, Moser F, Erard P, Verdon F, Studer JP, Villard G, et al. Community-acquired pneumonia. A prospective outpatient study. Medicine (Baltimore). 2001;80(2):75-87. doi:10.1097/00005792200103000-00001

31. Honeybourne D. Community-acquired pneumonia in ambulatory patients: relative importance of atypical pathogens. Int J Antimicrob Agents. 2001;18 Suppl 1(SUPPL.1):57-61. doi:10.1016/S09248579(01)00398-3

32. Cunha BA. Ambulatory community-acquired pneumonia: the predominance of atypical pathogens. Eur J Clin Microbiol Infect Dis. 2003;22(10):579-83. doi:10.1007/S10096-003-0996-1

33. Yu VL, Plouffe JF, Castellani-Pastoris M, Stout JE, Shousboe M, Widmer A. Distribution of Legionella species and serogroups isolated by culture in patients with sporadic community-acquired legionellosis: an international collaborative survey. J Infect Dis. 2002;186(1):127-8. doi: $10.1086 / 341087$

34. Cianciotto NP, Stamos JK, Kamp DW. Infectivity of Legionella pneumophila mip mutant for alveolar epithelial cells. Curr Microbiol. 1995;30(4):247-50. doi:10.1007/BF00293641

35. Payne NR, Horwitz MA. Phagocytosis of Legionella pneumophila is mediated by human monocyte complement receptors. J Exp Med. 1987;166(5):1377-89. doi:10.1084/JEM.166.5.1377

36. Fraser DW, Tsai TR, Orenstein W, Parkin WE, Beecham HJ, Sharrar RG. Legionnaires' disease: description of an epidemic of pneumonia. N Engl J Med. 1977;297(22):1189-97. doi:10.1056/NEJM197712012972201

37. Tsai TF, Finn DR, Plikaytis BD, Mccauley WILLIAM, Martin SM, Fraser DW. Legionnaires' disease: clinical features of the epidemic in Philadelphia. Ann Intern Med. 1979;90(4):509-17. doi:10.7326/00034819-90-4-509

38. Sopena N, Sabrià-Leal M, Pedro-Botet ML, Padilla E, Dominguez J, Morera $\mathrm{J}$, et al. Comparative study of the clinical presentation of Legionella pneumonia and other community-acquired pneumonia. Chest. 1998;113(5):1195-200. doi:10.1378/CHEST.113.5.1195

39. Isenman HL, Chambers ST, Pithie AD, MacDonald SL, Hegarty JM, Fenwick JL, et al. Legionnaires' disease caused by Legionella longbeachae: Clinical features and outcomes of 107 cases from an endemic area. Respirology. 2016;21(7):1292-9. doi:10.1111/RESP.12808
40. Franco-Garcia A, Varughese TA, Lee YJ, Papanicolaou G, Rosenblum MK, Hollmann TJ, et al. Diagnosis of Extrapulmonary Legionellosis in Allogeneic Hematopoietic Cell Transplant Recipients by Direct 16S Ribosomal Ribonucleic Acid Sequencing and Matrix-Assisted Laser Desorption/Ionization Time-of-Flight Mass Spectrometry. Open forum Infect Dis. 2017;4(3). doi:10.1093/OFID/OFX140

41. Banderet F, Blaich A, Soleman E, Gaia V, Osthoff M. Septic arthritis due to Legionella cincinnatiensis: case report and review of the literature. Infection. 2017;45(4):551-5. doi:10.1007/S15010-0160964-1

42. Barigou M, Cavalie L, Daviller B, Dubois D, Mantion B, Delobel P, et al. Isolation on Chocolate Agar Culture of Legionella pneumophila Isolates from Subcutaneous Abscesses in an Immunocompromised Patient. J Clin Microbiol. 2015;53(11):3683-5. doi:10.1128/JCM.01116-15

43. Han JH, Harada S, Edelstein PH, Nguyen JC, Baddour LM. Relapsing Legionella pneumophila cellulitis: a case report and review of the literature. J Infect Chemother. 2010;16(6):439-42. doi:10.1007/S10156-010-0072-6

44. Schaumann R, Pönisch W, Helbig JH, Hegenbart U, Ackermann G, Hofmann J, et al. Pericarditis after allogeneic peripheral blood stem cell transplantation caused by Legionella pneumophila (non-serogroup 1). Infection. 2001;29(1):51-3. doi:10.1007/S15010-001-0062-9

45. Ishimaru N, Suzuki H, Tokuda Y, Takano T. Severe Legionnaires' disease with pneumonia and biopsy-confirmed myocarditis most likely caused by Legionella pneumophila serogroup 6 . Intern Med. 2012;51(22):3207-12. doi:10.2169/INTERNALMEDICINE.51.7952

46. McClelland MR, Vaszar LT, Kagawa FT. Pneumonia and osteomyelitis due to Legionella longbeachae in a woman with systemic lupus erythematosus. Clin Infect Dis. 2004;38(10):e102-6. doi: $10.1086 / 386322$

47. Fernández-Cruz A, Marín M, Castelo L, Usubillaga R, Martín-Rabadán P, Bouza E, et al. Legionella micdadei, a new cause of prosthetic joint infection. J Clin Microbiol. 2011;49(9):3409-10. doi:10.1128/JCM.00770-11

48. Dorman SA, Hardin NJ, Winn Jr WC. Pyelonephritis associated with Legionella pneumophila, serogroup 4. Ann Intern Med. 1980;93(6):835-7. doi:10.7326/0003-4819-93-6-835

49. Perpoint T, Jamilloux Y, Descloux E, Ferry T, Chidiac C, Lina G, et al. PCR-confirmed Legionella non-pneumophila meningoencephalitis. Med Mal Infect. 2013;43(1):32-4. doi:10.1016/J.MEDMAL.2012.12.001

50. Arnouts PJ, Verpooten GA, De Broe ME, Ramael MR, Van Marck EA, Ysebaert DK, et al. Legionella pneumophila peritonitis in a kidney transplant patient. Scand J Infect Dis. 1991;23(1):119-22. doi: $10.3109 / 00365549109023386$

51. Fukuta Y, Yildiz-Aktas IZ, William Pasculle A, Veldkamp PJ. Legionella micdadei prosthetic valve endocarditis complicated by brain abscess: case report and review of the literature. Scand J Infect Dis. 2012;44(6):414-8. doi:10.3109/00365548.2011.645506

52. Lowry PW, Blankenship RJ, Gridley W, Troup NJ, Tompkins LS. A cluster of legionella sternal-wound infections due to postoperative topical exposure to contaminated tap water. $\mathrm{N}$ Engl J Med. 1991;324(2):109-13. doi:10.1056/NEJM199101103240207

53. Guy SD, Worth LJ, Thursky KA, Francis PA, Slavin MA. Legionella pneumophila lung abscess associated with immune suppression. Intern Med J. 2011;41(10):715-21. doi:10.1111/J.1445-5994.2011.02508.X

54. Charles M, Johnson E, Macyk-Davey A, Henry M, Nilsson JE, Miedzinski L, et al. Legionella micdadei brain abscess. J Clin Microbiol. 2013;51(2):701-4. doi:10.1128/JCM.02160-12

55. Yung AP, Grayson ML. Psittacosis--a review of 135 cases. Med J Aust. 1988;148(5):228-33. doi:10.5694/J.1326-5377.1988.TB99430.X

56. Hughes P, Chidley K, Cowie J. Neurological complications in psittacosis: a case report and literature review. Respir Med. 1995;89(9):637-8. doi:10.1016/0954-6111(95)90236-8

57. Samra Z, Pik A, Guidetti-Sharon A, Yona E, Weisman Y. Hepatitis in a family infected by Chlamydia psittaci. J R Soc Med. 1991;84(6):347.

58. Jeffrey RF, More IA, Carrington D, Briggs JD, Junor BJ. Acute glomerulonephritis following infection with Chlamydia psittaci. Am J Kidney Dis. 1992;20(1):94-6. doi:10.1016/S0272-6386(12)80325-8

59. Verweij PE, Meis JF, Eijk R, Melchers WJ, Galama JM. Severe human psittacosis requiring artificial ventilation: case report and review. Clin Infect Dis. 1995;20(2):440-2. doi:10.1093/CLINIDS/20.2.440 
Al-Abbad et al.: An Overview on Atypical Pneumonia Clinical Features and Management Approach, Review Article

60. Macheta MP, Ackrill P, August PJ. Psittacosis, panniculitis and clofazimine. J Infect. 1994;28(1):69-71. doi:10.1016/S01634453(94)94223-4

61. Miyashita Y, Nakamori Y. A family outbreak of Chlamydia psittaci infection. Kansenshogaku Zasshi. 1996;70(4):377-81. doi:10.11150/KANSENSHOGAKUZASSHI1970.70.377

62. Foley JE, Nieto NC. Tularemia. Vet Microbiol. 2010;140(3-4):332-8. doi:10.1016/J.VETMIC.2009.07.017

63. Sjöstedt A. Tularemia: history, epidemiology, pathogen physiology, and clinical manifestations. Ann N Y Acad Sci. 2007;1105(1):1-29. doi:10.1196/ANNALS.1409.009

64. Weber IB, Turabelidze G, Patrick S, Griffith KS, Kugeler KJ, Mead PS. Clinical recognition and management of tularemia in Missouri: A retrospective records review of 121 cases. Clin Infect Dis. 2012;55(10):1283-90. doi:10.1093/CID/CIS706

65. Pedati C, House J, Hancock-Allen J, Colton L, Bryan K, Ortbahn D, et al. Notes from the Field: Increase in Human Cases of Tularemia-Colorado, Nebraska, South Dakota, and Wyoming, January-September 2015. MMWR Morb Mortal Wkly Rep. 2015;64(47):1317-8. doi:10.15585/MMWR.MM6447A4

66. Maurin M, Benoliel AM, Bongrand P, Raoult D. Phagolysosomal alkalinization and the bactericidal effect of antibiotics: the Coxiella burnetii paradigm. J Infect Dis. 1992;166(5):1097-102. doi:10.1093/INFDIS/166.5.1097

67. Raoult D, Marrie T. Q fever. Clin Infect Dis. 1995;20(3):489-96. doi:10.1093/CLINIDS/20.3.489

68. Hartzell JD, Wood-Morris RN, Martinez LJ, Trotta RF. Q fever: epidemiology, diagnosis, and treatment. Mayo Clin Proc. 2008;83(5):574-9. doi:10.4065/83.5.574

69. Dupuis G, Petite J, Péter O, Vouilloz M. An important outbreak of human $Q$ fever in a Swiss Alpine valley. Int $J$ Epidemiol. 1987;16(2):282-7. doi:10.1093/IJE/16.2.282
70. Woodhead MA, Macfarlane JT. Comparative clinical and laboratory features of legionella with pneumococcal and mycoplasma pneumonia. Br J Dis Chest. 1987;81(2):133-9. doi:10.1016/0007-0971(87)90130-6

71. Hammerschlag MR. Mycoplasma pneumoniae infections. Curr Opin Infect Dis. 2001;14(2):181-6. doi:10.1097/00001432-20010400000012

72. Hindiyeh M, Carroll KC. Laboratory diagnosis of atypical pneumonia. Semin Respir Infect. 2000;15(2):101-13. doi:10.1053/SRIN.2000.9592

73. Cunha BA. Atypical pneumonia. Clinical diagnosis and empirical treatment. Postgrad Med. 1991;90(5):89-101. doi:10.1080/00325481.1991.11701073

74. Cunha BA. Atypical pneumonia: Current clinical concepts focusing on Legionnaires' disease. Curr Opin Pulm Med. 2008;14(3):183-94. doi:10.1097/MCP.0B013E3282F79678

75. Carratalà J, Garcia-Vidal C. An update on Legionella. Curr Opin Infect Dis. 2010;23(2):152-7. doi:10.1097/QCO.0B013E328336835B

76. Pedro-Botet ML, Garcí-Cruz A, Tural C, Mateu L, Sopena N, Roure S, et al. Severe Legionnaires' disease successfully treated with levofloxacin and azithromycin. J Chemother. 2006;18(5):559-61. doi:10.1179/JOC.2006.18.5.559

77. Woodhead M, Blasi F, Ewig S, Garau J, Huchon G, Ieven M, et al. Guidelines for the management of adult lower respiratory tract infections--full version. Clin Microbiol Infect. 2011;17 Suppl 6(Suppl 6):E1-E59. doi:10.1111/J.1469-0691.2011.03672.X

78. Yung AP, Grayson ML. Psittacosis--a review of 135 cases. Med J Aust. 1988;148(5):228-33. doi:10.5694/J.1326-5377.1988.TB99430.X

79. Gikas A, Kokkini S, Tsioutis C. Q fever: Clinical manifestations and treatment. Expert Rev Anti Infect Ther. 2010;8(5):529-39. doi:10.1586/ERI.10.29

80. Farber IM, Kudryashova MA, Galstyan LA, Shatalina SI. Current aspects of antibacterial drug administration when treating nosocomial Pneumonia. J Adv Pharm Edu Res. 2021;11(1):29-34. 